\title{
LAZER E QUALIDADE DE VIDA NA TERCEIRA IDADE: PERSPECTIVA DE PROMOÇÃO DA SAÚDE
}

\section{RESUMO}

O projeto Lazer e qualidade de vida na terceira idade: perspectiva de promoção da saúde, desenvolvido no Campus Natal - Cidade Alta, destaca como objetivo promover atividades de lazer com caráter lúdico, proporcionando qualidade de vida aos idosos para que o envelhecimento não seja um período de perdas, podendo ser considerado um período de novas experiências. Para melhor desenvolvimento do projeto, utilizamos a metodologia colaborativa com atividades diversificadas sendo ministradas três vezes por semana. Como resultado inicial, pode-se destacar: 1) em relação às vivências em grupo, percebemos a dificuldade de cada um, mas também as vitórias conquistadas a cada dia; 2) melhores relações de afeto; 3) o olhar atento; 4) a alegria em estarem fazendo atividades com pessoas que, com todas as dificuldades, estão ali em busca de mudar seu dia, sorrir, brincar, viver intensamente.

Palavras-Chave: Qualidade de Vida. Terceira idade. Promoção da saúde

\section{INTRODUÇÃO}

O novo perfil demográfico e as demandas crescentes para os idosos apontam para o avanço de providências e estratégias nas áreas da saúde, educação e de desenvolvimento social. Quanto ao atendimento à população que envelhece, algumas ações sociais e educativas devem ser desenvolvidas devido ao estilo de vida sedentário de muitos idosos, decorrente do seu isolamento, e à preconcepção de envelhecimento como deca- dência e inaptidão. Essa temática tem sido amplamente discutida na área do lazer, visto que a atividade lúdica é tida como uma forma de amenizar o sedentarismo.

Programas de lazer, esportes e atividades físicas relacionados ao envelhecimento têm se destacado em vários estudos (BENEDETTI, 2004; CARDOSO, 2009; GEREZ, 2007), promovendo muitos benefícios e a prevenção de diversas patologias. O lazer, além de ser indicado para a promoção da saúde e qualidade de vida do idoso, 
também contribui melhorando o convívio social, o bem-estar, a autoestima e a autoimagem, já que o processo de envelhecimento acarreta mudanças no indivíduo, nos aspectos físicos, sociais e psicológicos. Partindo dos benefícios que as atividades de lazer podem proporcionar a população idosa, percebeu-se a necessidade em 2013 de um projeto em lazer e qualidade de vida para terceira idade na perspectiva da promoção da saúde. Esse projeto vem sendo desenvolvido no IFRN - Campus Cidade Alta, em sua segunda edição neste ano de 2014, contemplando atividades de lazer para população idosa, valorizando suas potencialidades em todos os segmentos, favorecendo a descontração, momentos de liberação, de cooperação, de interação, de criatividade e de aquisição de conhecimentos, contribuindo para a vida em grupo e consequentemente para uma verdadeira qualidade de vida na terceira idade.

\section{DESENVOLVIMENTO}

Para o desenvolvimento do projeto Lazer e qualidade de vida na terceira idade: perspectivas de promoção da saúde utilizou-se a metodologia colaborativa, que consistiu numa equipe composta por uma professora-coordenadora e duas alunas bolsistas.

\subsection{Atividades desenvolvidas}

No início das atividades, foi realizado um diagnóstico por meio de entrevista utilizando-se um questionário socioeconômico, psicossocial e anamnese de saúde, para conhecer a realidade dos idosos, suas relações e limitações com a atividade física, os tipos de doenças, os medicamentos utilizados e o nível de satisfação com a vida financeira, com a saúde e com as relações sociais. Também nesta fase aplicamos um questionário de avaliação autofuncional, o qual avaliava a percepção dos idosos com relação às atividades básicas da vida diária e uma avaliação física contendo os testes de resistência cardiorrespiratória, de força, flexibilidade, equilíbrio estático e dinâmico e as medidas antropométricas.

As atividades foram ministradas três vezes por semana, no horário das $7 \mathrm{~h}$ às $11 \mathrm{~h}$, incluindo caminhada, alongamento, dinâmicas de grupo, atividades rítmicas e recreativas, dança e atividades manuais. Todas as atividades praticadas foram realizadas na sala de dança e no pátio de convivência do IFRN - Campus Cidade Alta duran- te a semana e uma vez por mês na comunidade onde os idosos residiam. Para o desenvolvimento das atividades, sistematizamos cada encontro com os idosos em quatro momentos: no primeiro momento eram realizadas atividades de alongamento e aquecimento; no segundo momento, dança, atividades rítmicas e recreativas, variando semanalmente; no terceiro momento desenvolvíamos atividades de relaxamento e massagem; e no quarto momento, compartilhávamos dinâmicas de grupos e atividades manuais.

\subsection{Acompanhamento das atividades de} lazer

Para acompanhamento do projeto, foram desenvolvidas as seguintes ações: 1 . realização de reuniões semanais com três horas de duração para planejamento e andamento das atividades do projeto; 2 . mensalmente ocorriam reuniões com os idosos, monitoras e coordenadora a fim de avaliar o andamento do projeto, e eram colocadas sugestões e críticas pelos participantes do projeto; 3 . ao final do projeto, para encerramento, foram realizadas confraternizações entre os idosos, monitoras e a coordenadora do projeto, organizadas pelos idosos e alunos do curso de Gestão Desportiva e de Lazer, possibilitando o compartilhar de todas as vivências realizadas durante todo tempo do projeto.

\section{TERCEIRA IDADE EM AÇÃO}

Por meio de dinâmicas de grupo, oficinas de jogos, atividades manuais, vivências lúdicas e outras atividades, observamos o aumento na força muscular, na mobilidade articular, no equilíbrio, melhorias na coordenação, na capacidade aeróbica e respiração.

Nas atividades manuais, percebemos a concentração e dedicação no desenvolvimento das ações, preservando os movimentos das mãos que o corpo ainda possui. 

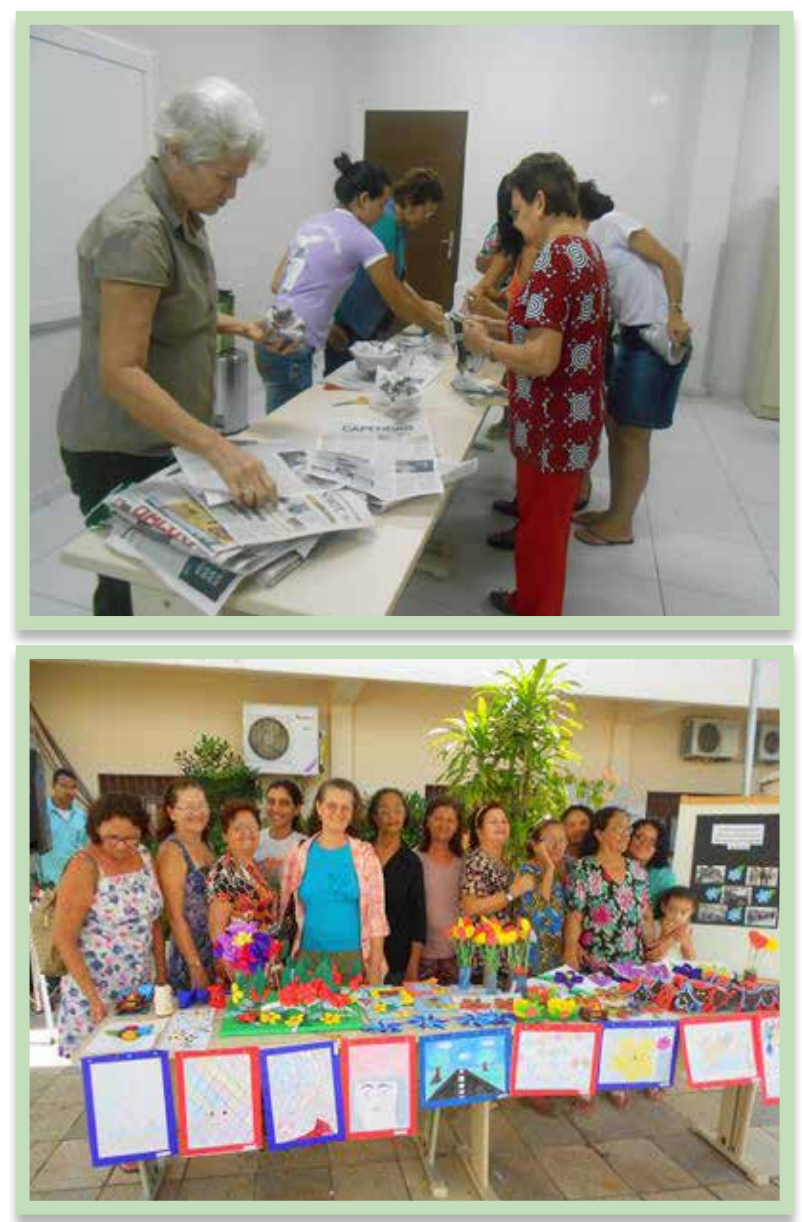

Figura 1: Exposição das atividades manuais

Eram notórios o olhar atento e a alegria de estarem fazendo atividades com outros idosos que, com todas as dificuldades, estavam ali em busca de mudar seu dia, sorrir, brincar, viver intensamente.

Observamos que, no decorrer das atividades de passeio e momentos de compartilhar saberes através da poesia, houve uma melhoria nas relações sociais, melhorando a socialização integralmente, possibilitando autoconfiança e elevando a autoestima.

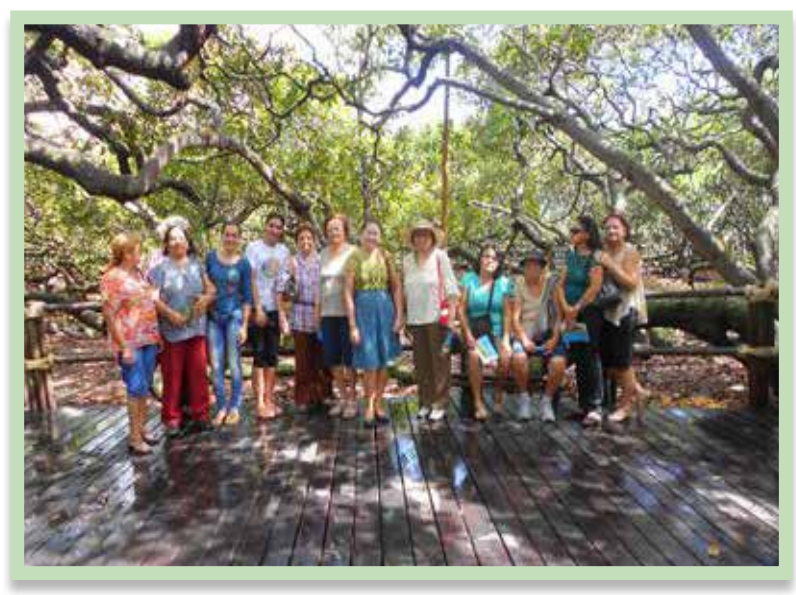

Figura 2: Passeio turístico

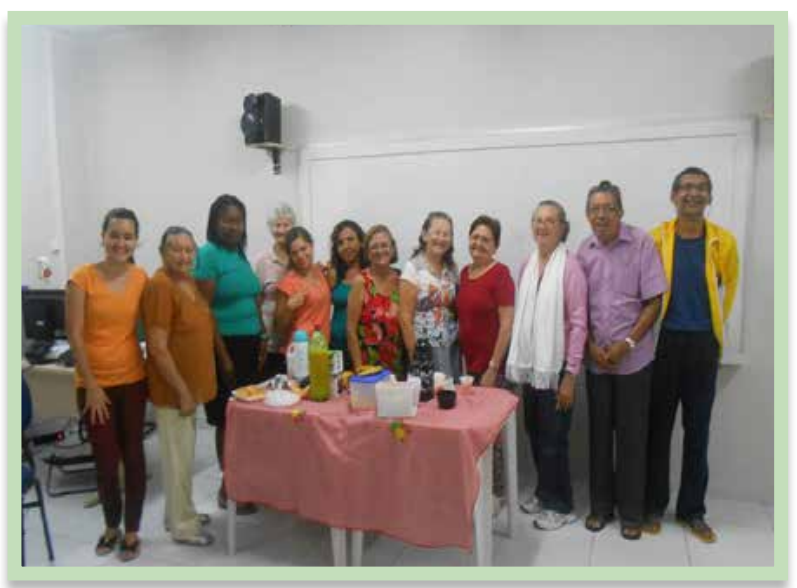

Figura 3: Café com poesia

A realização de atividades sem obrigatoriedade e, acima de tudo, de livre escolha, auxilia o idoso na manutenção de seu equilíbrio físico e social, afastando-o do processo de isolamento, da vulnerabilidade a doenças.

\section{CONCLUSÕES}

O projeto evidenciou a importância de garantir aos idosos não só uma sobrevida maior, mas também uma boa qualidade de vida, que está relacionada à autoestima e ao bem-estar pessoal, abrangendo uma série de aspectos como a capacidade funcional, o nível socioeconômico, o estado emocional, a interação social, a atividade intelectual, o autocuidado, o suporte familiar, o próprio estado de saúde, os valores culturais, o estilo de vida, a satisfação com o emprego e/ou com atividades diárias e o ambiente em que se vive.

No processo de continuidade, acrescentamos, neste ano de 2014, ações intergeracionais, facilitando a aproximação das faixas etárias e beneficiando mutuamente as gerações, no sentido do aprimoramento dos conhecimentos em relação à história familiar, à cidade onde residem, ao mundo e fora do contexto familiar. Tudo isso pode facilitar o estabelecimento de uma nova amizade/ afetividade que desencadeie a solidariedade e o desenvolvimento cognitivo social. A convivência de pessoas de diferentes gerações significa também a convivência entre diferentes culturas. Segundo alguns autores, como Ferrigno (2003), na relação intergeracional há troca e aprendizado de ambas as partes por meio do ponto de vista de cada geração, de acordo com suas experiências históricas. 


\section{REFERÊNCIAS}

BENEDETTI, T.R.B. Atividade Física: uma perspectiva de promoção de saúde do idoso no município de Florianópolis. 2004. Tese (Doutorado em Enfermagem) -

Programa de Pós-Graduação em Enfermagem, Florianópolis: Universidade Federal de Santa Catarina, 2004.

CARDOSO, M. Parques colocam idosos para malhar. 18 mar. 2009. Disponível em : <http:// www.estadao.com.br> Acesso em: 22 mar. 2009, 00:32:12

DAVIM, R. M. B. et al. Estudo de idosos institucionalizados no município de Natal/RN: Características socioeconômicas e de saúde. Revista Latinoamericana de Enfermagem, Ribeirão Preto, v. 12 , n. 3, p. 518-24, maio/jun. 2004.

FERRIGNO, J. C. Co-educação entre gerações. Petrópolis, RJ: Vozes; São Paulo: SESC, 2003.

GEREZ, A V; MIRANDA, M L J; CAMARA, F M; VELARDI, M. A Prática Pedagógica e a Organização Didática dos Conteúdos de Educação Física para Idosos no Projeto Sênior para a Vida Ativa da USJT: uma experiência rumo à autonomia. Revista Brasileira de Ciências do Esporte, Vol. 28, n. 2, 2007. 